\title{
НОВЫЕ ДАННЫЕ О СВЯЗИ МЕЖДУ НАПРАВЛЕНИЯМИ ДОЛИН И ТЕКТОНИЧЕСКОЙ ТРЕЩИНОВАТОСТЬЮ В СЕВЕРНОЙ ЭСТОНИИ
}

Предполагается, что направление долин Северной Эстонии предопределено главным образом тектоникой, в частности тектонической трешиноватостью (Tammekann, 1926; Teichert, 1927; Мийдел, 1966). Однако в подтверждение такого взгляда пока приведено недостаточно фактов. Ниже приводятся некоторые новые данные о тектонической трещиноватости в руслах рек Северной Эстонии преимущественно вблизи водопадов, т. е. в местах, где реки прорывают Северо-Эстонский глинт.

В долине р. Валгейыги, у водопада Ныммевески, русло разбито трещинами северо-западного простирания (азимуты $300-310^{\circ}$ ) через каждые 2-4 м. Вдоль реки наблюдаются также редкие северо-восточные трещины с азимутами $30-45^{\circ}$. Общее направление долины здесь северовосточное $\left(20^{\circ}\right)$, но после выхода реки из каньона, оно меняется на северо-западное $\left(300^{\circ}\right)$. С направлением северо-западных трещин совпадает простирание глинта между дд. Колга и Ныммевески и древней долины в глинтовой бухте Валгейые-Лообу.

Четкие северо-западные трещины с азимутами 290-310 даются также в русле и на берегах р. Лообу у водопада Иоавески (табл. I, I). Эти трещины частично разграничивают русло, но уступы коренных пород связаны с трецинами северо-восточного простирания (преобладают азимуты $50-70^{\circ}$ ). На врезающемся в коренные породы участке направление долины северо-западное $\left(310^{\circ}\right)$. Вниз по течению от водопада, где река врезается в четвертичные отложения, направление долины меняется на северное.

В долине р. Селья у д. Варангу явно преобладают хорошо выраженные трещины северо-западного простирания с азимутами $310-330^{\circ}$. Северо-восточные трещины $\left(60-80^{\circ}\right)$ встречаются очень редко. Общее направление долины, точнее древней долины, используемой в настоящее время рекой, северо-западное $\left(338^{\circ}\right)$.

Наибольший интерес представляет, на наш взгляд, долина р. Пада между дд. Самма и Койла. У д. Самма, в верхнем течении реки, широко распространены карстовые явления, в засушливые периоды года река течет даже под землей. По нашим наблюдениям здесь преобладают трещины северо-восточного простирания с азимутами $10-30^{\circ}$ (рисунок, табл. I, 2). Реже встречаются северо-западные трещины. Ширина некоторых открытых трещин достигает $8 \mathrm{~cm}$. Вода поглощается и поднимается по северо-восточным трещинам (преобладают азимуты $50-60^{\circ}$ ). Общее направление долины на этом участке (рисунок, линия $Б$ ) неплохо совпадает с преобладающей тектонической трещиноватостью. Более того, 


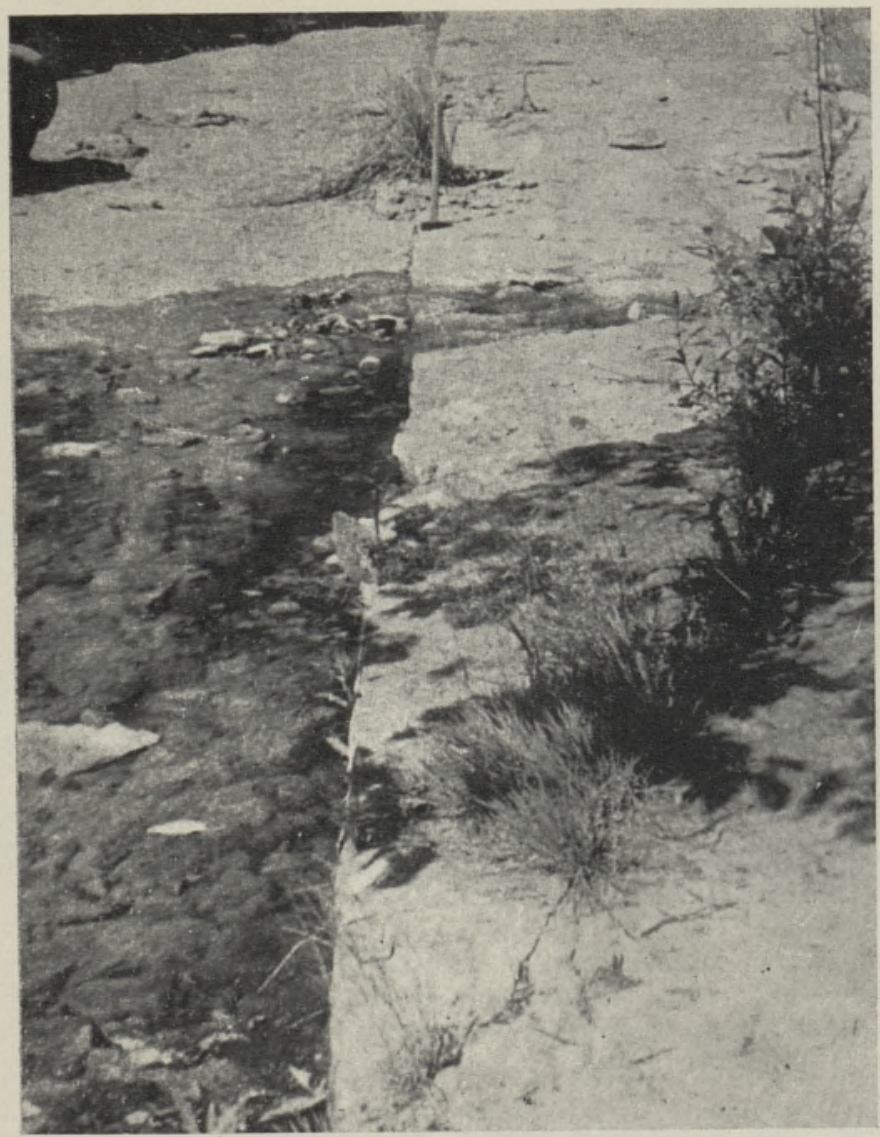

1. Тектонические трещины в долине р. Лообу, у водопада Йавески.

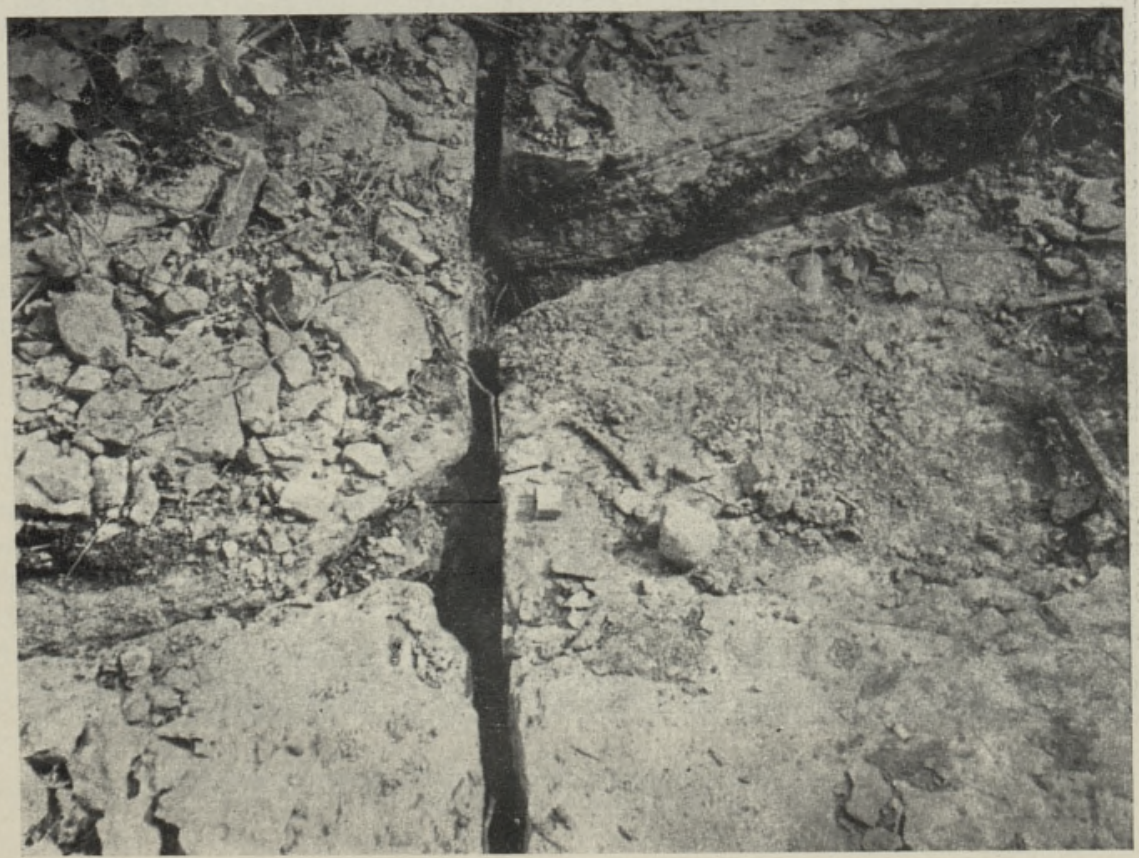

2. Открытые тектонические трещины в русле р. Пада у д. Самма. 


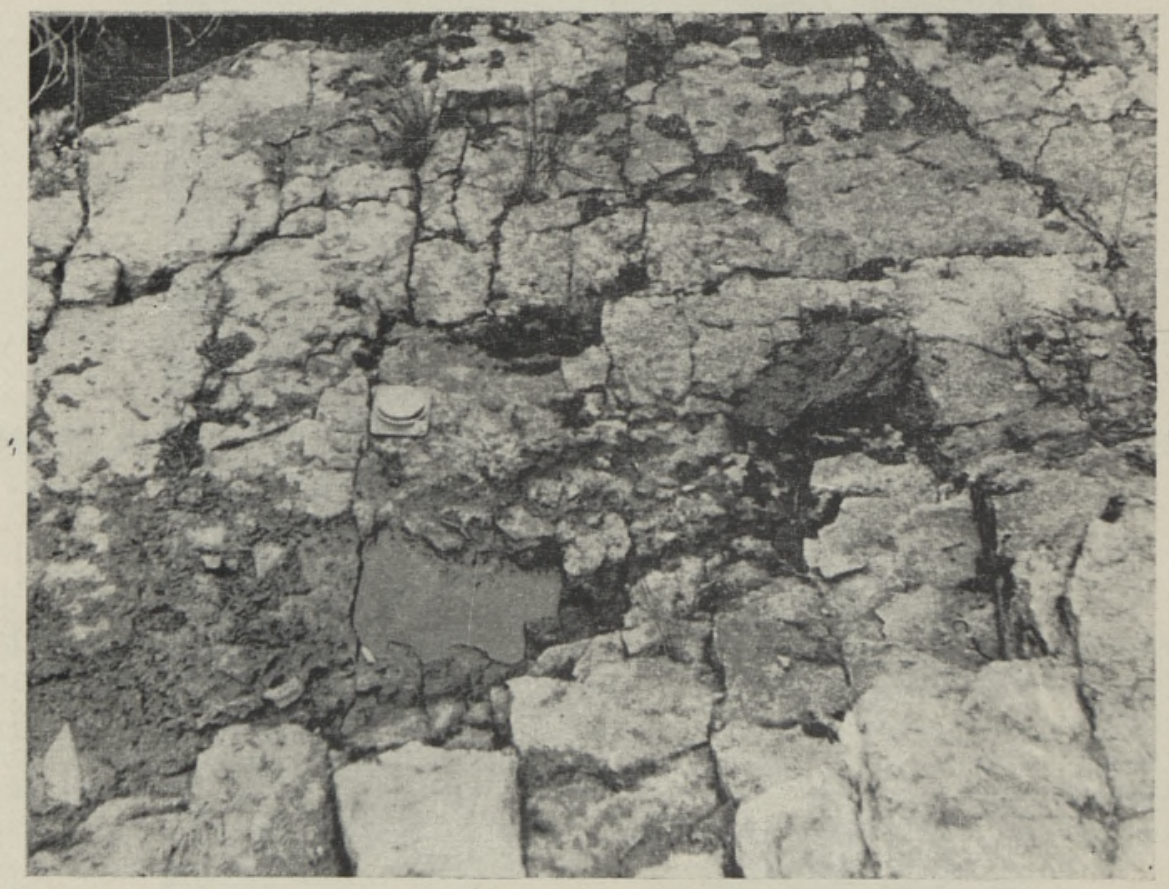

3. Густая тектоннческая трещиноватость (зона дробления?) у водопада Лангезоя.

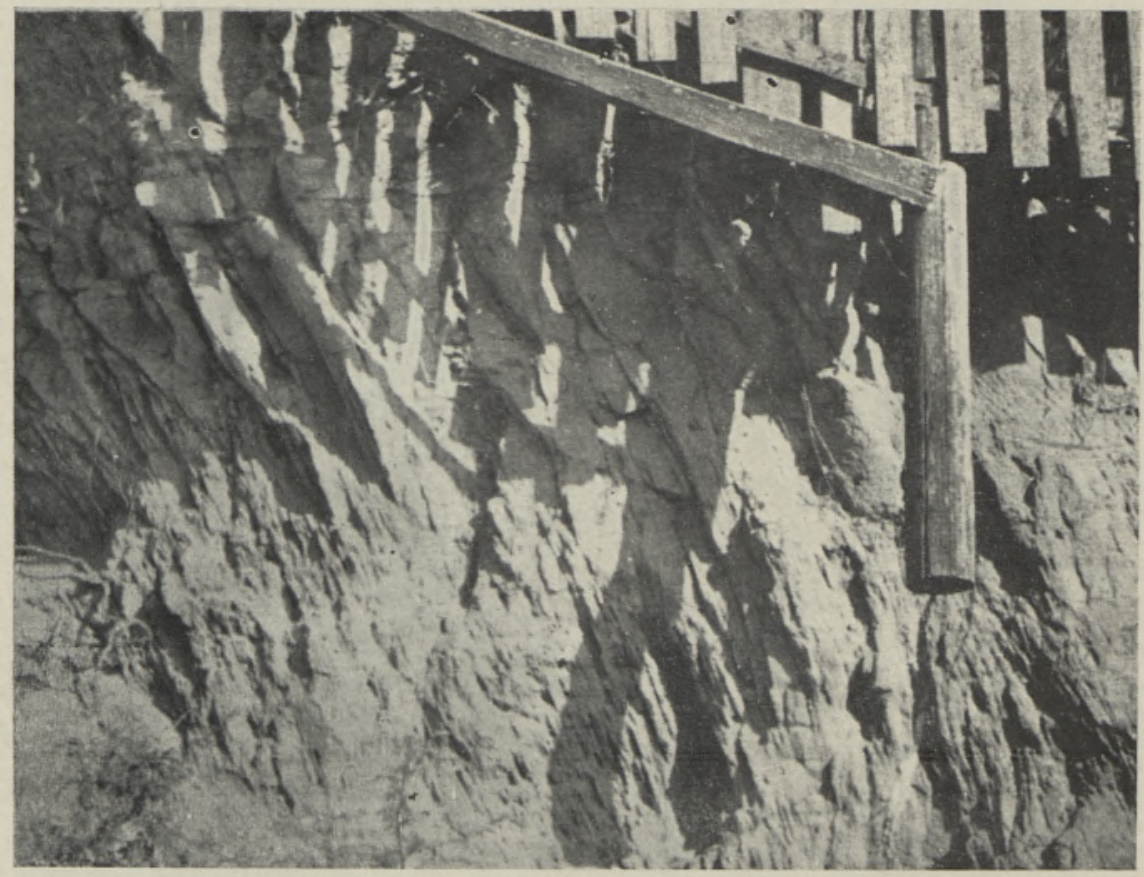

4. Сильно трешиноватые девонские песчаники на левом склоне p. Эмайыги в r. Тарту 
вероятно, что общее направление долины р. Пада между дд. Самма и Койла (рисунок, линия $A$ ) также связано с трещиноватостью северо-восточного простирания. На это указывают и такие признаки, обычно приписываемые к тектонически обусловленным долинам, как прямолинейность и узость долины, а также еe V-образная форма с крутыми, местами даже обрывистыми склонами. Интересно отметить, что при пересечении с Азериским тектоническим нарушением направление долины не менястся. Влияние названного нарушения незаметно также и в случае долины р. Кунда.

У водопада Лангевоя, расположенного в долине левого притока р. Сытке, встречаются хорошо выраженные трещины северо-восточного простирания $\left(30-40^{\circ}\right)$ и густая трещиноватость близ кого $\left(3-15^{\circ}\right)$ простирания (табл. II, 3),

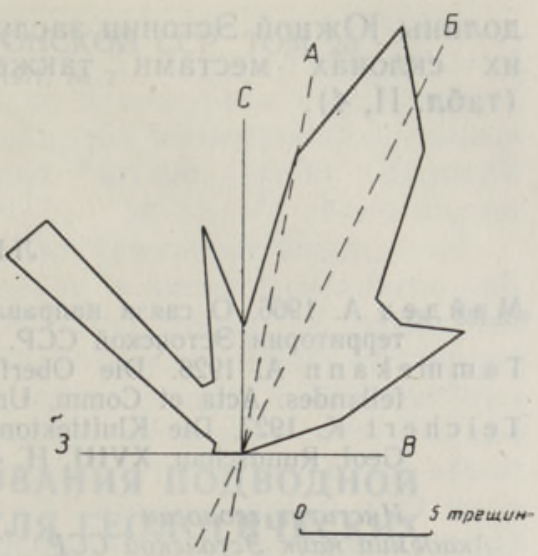

Роза трещиноватости карбонатных пород в верхнем течении р. Пада: у д. Самма.

$A$ - направление долины р. Пада. между дд. Самма и Койла; $B-$ направление долины р. Пада у д. Самма. что приблизительно совпадает с направлением долины (вначале северное, несколько ниже по течению от водопада - северо-восточное с азимутом $40^{\circ}$ ). Расстояние между густо расположенными трещинами составляет в среднем $0,1-0,3 \mu$. Благодаря: этим трещинам край водопада имеет зубчатый характер. На краю водопада имеется выемка, образованная тектонической трещиной с азимутом $35^{\circ}$. Северо-западные трещины у водопада встречаются редко.

На небольшом ручье, несколько километров западнее г. Нарвы, расположен водопад Тырвайыэ. На поверхности известняков здесь наблюдается очень густая трещиноватость (расстояние между трещинами $0,15-0,20 \mu)$ северо-западного простирания с азимутами $330-340^{\circ}$. Главная струя воды течет по трещине с азимутом $330^{\circ}$. Общее направление ручья вблизи водопада также северо-западное $\left(\sim 320^{\circ}\right)$. Левый склон каньона разбит трещинами того же простирания. Северо-восточные трещины более редки. Выходя из каньона, направление ручья меняется на северо-восточное $\left(17^{\circ}\right)$. Там склоны долины низкие и состоят из четвертичных отложений.

Все эти примеры приведены для районов, где трещины одного направления более или менее преобладают. Но имеются случаи, когда одинаково развиты две перпендикулярные системы трещин, как например у водопада Ягала. В этом случае долина может развиваться по результирующему направлению. У водопада Ягала* развиты северо-западные $\left(310^{\circ}\right)$ и северо-восточные $\left(40^{\circ}\right)$ трещины, а направление каньона, возникшего в ходе отступания водопада, строго западное.

Чтобы получить более убедительные выводы о связи между направлением долин и тектонической трещиноватостью, конечно, необходимо иметь не только качественные, но и количественные данные о трещиноватости, в том числе данные о густоте трещин разного направления. Но тем не менее приведенный выше материал, по нашему мнению, подтверждает направляющую роль тектонической трещиноватости в заложении речных долин Северной Эстонии. Нужно добавить, что с этой точки зрения и

* По материалам дипломной работы X. Аунина. 
долины Южной Эстонии заслуживают подробного изучения, так как на их склонах местами также развита интенсивная трещиноватость (табл. II, 4).

\title{
ЛИ ТЕ РА Т У Р А
}

-М и йде л А. 1966. О связи направлений долин с тектонической трещиноватостью на территории Эстонской ССР. Ежегодн. Эстонск. геогр. об-ва 1964/1965. Таллин. T a mmekan n A. 1926. Die Oberflächengestaltung des Nordestländischen Küstentafellandes. Acta et Comm. Univ. Tartuensis, A, X.

Teichert K. 1927. Die Klufttektonik der Cambrosilurischen Schichtentafel Estlands. Geol. Rundschau, XVIII, H. 4.

\author{
Институт геологии \\ Академии наук Эстонской ССР
}

Поступила в редакцию 30/XII 1970

\section{A. MIIDEL}

\section{UUSI ANDMEID PÕHJA-EESTI ORGUDE JA TEKTOONILISTE LÖHEDE SUUNDADE VAHELISEST SEOSEST}

Autor mõōtis ordoviitsiumi kivimites esinevate tektooniliste lōhede (joon., tab. I, 1-2, tab. II, 3) suundasid Pōhja-Eesti paekallast ületavate jōgede orgudes, peamiselt jugade läheduses, ning võrdles tulemusi oru suunaga mōōtmiskohas, Kōigil juhtudel näivad domineerivat tektoonilised lōhed, millede suund ühtub oru suunaga. Seepärast oletatakse, et neil lōhedel on olnud oluline osa jōgede voolusuuna kujunemises. Osutatakse vajadusele uurida sellest seisukohast ka Lõuna-Eesti orgudes esinevat lōhelisust, mis kohati on intensiivne (tab. II, 4).

\section{A. MIIDEL}

\section{NEW DATA ON THE INTERDEPENDENCE OF THE DIRECTIONS OF NORTH- ESTONIAN VALLEYS AND TECTONIC JOINTS}

The author effected measurements of the directions of tectonic joints (Fig., Table I, $1-2$; Table II, 3) occurring in the Ordovician rocks in the valleys of rivers crossing the North-Estonian Glint, mainly in the vicinity of waterfalls. The results were compared to the direction of the valley in the places where measurements were effected. In all the cases, those tectonic joints seemed to predominate, whose direction coincided with that of the valley, for which reason it may be assumed that the tectonic joints played an important role in the formation of the direction of the river-flow. The author points to the necessity of effecting similar researches into the intensive tectonic joints in South-Estonian river valleys (Table II, 4), as well. 